\title{
Visual fatigue: The need for an integrated model
}

\author{
FREDERICK V. MALMSTROM \\ Institute of Safety and Systems Management \\ University of Southern California, Los Angeles, California 90007
}

ROBERT J. RANDLE and MILES R. MURPHY

National Aeronautics and Space Administration/Ames Research Center, Moffett Field, California 94035

LAWRENCE E. REED

Air Force Human Resources Laboratory, Wright-Patterson Air Force Base, Ohio 45433

and

ROBERT J. WEBER

Oklahoma State University, Stillwater, Oklahoma 74074

\begin{abstract}
Two experiments were conducted to examine possible decrements in performance over time on two visual tracking tasks. In Experiment 1, six subjects tracked a horizontal, sinusoidally moving target in the picture plane for $6.5 \mathrm{~min}$. In Experiment 2, six subjects tracked a target sinusoidally changing focus in the depth plane between 0 and $4 \mathrm{D}$ over $6.5 \mathrm{~min}$. Results indicated a linearlly decreasing amplitude of both pursuit eye movements (.29 deg of visual angle per minute) and accommodation $(.11 \mathrm{D} / \mathrm{min})$. These visual fatigue effects are discussed in the context of several competing explanations.
\end{abstract}

Reviews of visual fatigue literature (Smith, 1979; Tinker, 1958) have pointed out the lack of a satisfactory definition of the response measures. There is no author who denies that visual fatigue exists; however, subjective and objective measures are not always highly correlated. The lack of agreement between the types of measures has left the study of visual fatigue with little evidence of progress for the past 30 years.

An immediate area of investigation usually seems to be the effects of prolonged eye movements on the extraocular muscles. There have been heroic attempts to induce fatigue in eye movements, such as requiring subjects to read up to $6 \mathrm{~h}$ of a treatise on economics (Carmichael \& Dearborn, 1951). Surprisingly, the response measures showed little or no decrement in either eye movements or comprehension. Perhaps a better question would be not how it is possible to fatigue the extraocular muscles, but why it is so difficult to fatigue them.

Requests for reprints should be sent to Miles R. Murphy, Mail Stop 239-3, NASA/Ames Research Center, Moffett Field California 94035 . Support was provided by the Man-Vehicle Systems Research Division, NASA/Ames Research Center, Moffett Field, California, the Air Force Human Resources Laboratory (AFHRL), Wright-Patterson Air Force Base, Ohio, and the Rome Air Development Center, Griffiss Air Force Base, New York. However, no endorsement by any agency should necessarily be implied. The authors express their appreciation to Donna L. Miller, Informatics, Inc., and Bill Shelker and Ed Sanderlin of AFHRL for technical assistance.
Subjective measures of visual fatigue, such as reports of blurred and double vision, burning eyes, inflamed eyelids, and so on (Ferguson, Major, \& Keldoulis, 1974), are by no means unique measures of fatigue; neither do these symptoms tend to identify the source of the problem. It is the lack of reliable, objective measures of visual fatigue that has prompted some authors to relate visual fatigue to environmental and personality factors (Dainoff, Happ, \& Crane, 1980).

Objective visual fatigue symptoms can be produced with some difficulty in both the field and the laboratory, but the interpretations of why they occur are often contradictory (Smith, 1979). Basically, the results of short-term (acute) visual fatigue experiments seem to say that a constant alternation of the focus of a target will produce a decreased range of accommodation (Weber, 1950); a long-term industrial visual inspection task will effect a chronic, linear shift of accommodation to the visual far point (Saito \& Tanaka, in press). Both longterm and short-term viewing of technical displays will effect a pupillary constriction (Geacintov \& Peavler, 1974).

As is often cited in examples like the well documented "near reflex" (Davson, 1976, pp. 387), variables that affect accommodation will also tend to affect the pupillary response. With the visual system, it is difficult to do just one thing. To this point, the literature has almost totally ignored the interactive effects of vergence, pupillary response, eye movements, and accommodation. 
In our view, the most promising measures of fatigue involve pursuit tracking in the picture plane and dynamic accommodative tracking in the depth plane. We examine these measures in Experiments 1 and 2, respectively.

\section{EXPERIMENT 1: PURSUIT EYE MOVEMENTS}

A recent study by Malmstrom, Reed, and Randle (Note 1) indicated that pursuit eye movements could be severely restricted by the addition of a concurrent auditory monitoring task. This effect was predicted largely on the reasoning that sympathetic arousal would manifest itself in the restriction of pursuit eye movements, not unlike the well documented pupillary dilation response to mental work load (Kahneman, Peavler, \& Onuska, 1968). The experiments by Geacintov and Peavler (1974), however, indicated a pupillary constriction as evidence of visual fatigue, a possible generalized parasympathetic response. Therefore, if parasympathetic effects were implicated in visual fatigue, it would be reasonable to also expect an increase in the amplitude of pursuit eye movements.

\section{Method}

Subjects. The subjects were six adults, ages 21 to 31 years, with at least a high school education. Five were volunteer male Air Force officers and the sixth was a paid female. All had just completed a 2 -h eye movement experiment unrelated to visual fatigue. There were no requirements for visual acuity, but subjects were not permitted to wear eyeglasses, to preclude the possibility that eyeglass frames might limit their peripheral vision.

Apparatus. All measurements were taken with a Gulf + Western $1994 \mathrm{~S}$ oculometer with a resolution of about $.25 \mathrm{deg}$ of visual angle; the head was held in place with a hot-wax molded bite bar. The data were recorded in digital form at 30 sampled points per second and were later replotted in analog form. Room illumination was held at about $150 \mathrm{~cd} / \mathrm{m}^{2}$. The target was generated onto a cathode-ray tube $71 \mathrm{~cm}$ from the subject's left eye as a horizontally moving spot generated at $.4 \mathrm{~Hz}$ sinusoidally through a visual angle of $18 \mathrm{deg}$.

Instructions and Procedure. Each subject was informed that this was an experiment designed to measure his/her ability to track a constantly moving target for $6.5 \mathrm{~min}$.

\section{Results and Discussion}

Figure 1 indicates the mean pursuit eye movement range, in degrees of visual angle, over 13 consecutive 30 -sec time blocks (6.5 min).

Each subject's data point consists of 12 averaged peak-to-peak amplitude values for each 30-sec interval. Over the entire $6.5-\mathrm{min}$ trial, the subjects tended to go from an initial range of 15.4 deg to a 14.3-deg range of visual angle, or about a $9 \%$ loss of pursuit eye movement range. A best-fit linear least squares line through the data indicates a slope of $.143 \mathrm{deg}$ per time block, or $-.286 \mathrm{deg}$ of visual angle per minute.

A simple analysis of variance for task effects over the 13 time blocks revealed a significant effect $[F(12,60)=$ $7.883, \mathrm{p}<.001]$. An analysis of variance test for linear and curvilinear regression (Hays, 1973, pp.685) also

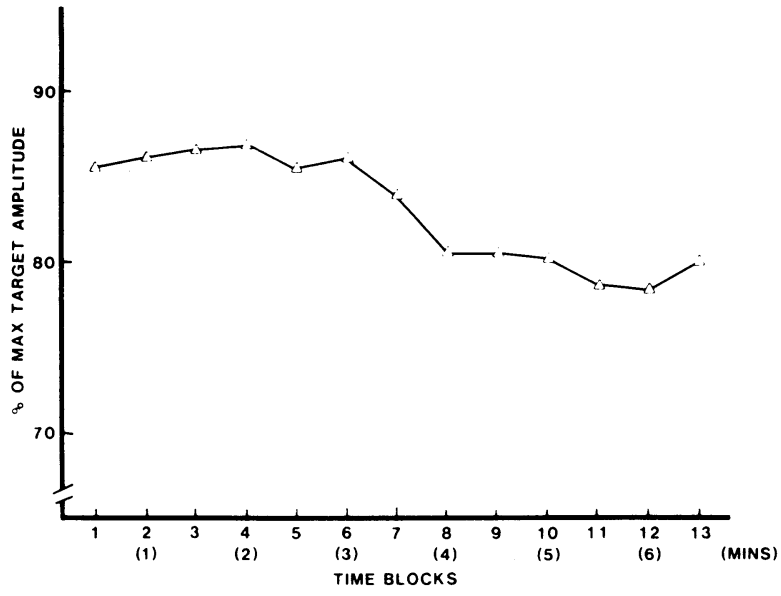

Figure 1. Mean pursuit eye movement amplitude over 6.5 min of tracking a horizontal sinusoidal target, as a percentage of target amplitude, in degrees of visual angle. $(N=6$.)

indicated that the plot in Figure 1 is overwhelmingly linear $[F(1,60)=59.220, p<.001]$. An analysis of variance for the phase lag of the eye to the target stimulus failed to detect time phase differences in tracking over time blocks $(\mathrm{F}<1)$. It is evident, therefore, that the subjects had no difficulty in keeping pace with the target although the range of movement appears restricted.

\section{EXPERIMENT 2: ACCOMMODATION}

If, as was also suggested by Malmstrom, Randle, Bendix, and Weber (1980), visual fatigue were to manifest itself as a cumulative parasympathetic response, then it would be reasonable to expect a gradual, linear shift of the accommodative response from the far to the near point, compatible with the pupillary constriction found in Geacintov and Peavler (1974). Previously, visual fatigue studies have been in conflict over the expected direction of the accommodation shift (Smith, 1979). However, all studies seem to have used a subjective measure of determining visual accommodation, such as the Badal optometer; hence, there is no direct, objective method of determining the accommodative shift, if any.

\section{Method}

Subjects. The subjects were six paid males, ages 19 to 23 years, with at least a high school education. The subjects were screened from previous accommodation experiments to insure that they had at least 20/20 vision (near and far) determined by a Bausch and Lomb orthorater, and a 4.0-D (diopter $=\mathrm{m}^{-1}$ ) range of accommodation. They were familiar with the experimental apparatus.

Apparatus. All measurements were taken with the Cornsweet and Crane (1970) objective optometer. Two pieces of apparatus were used. The first, the optometer, is an infrared, continuously nulling (servocontrolled) device based on the familiar Scheiner principle (Davson, 1976, pp. 397). A retinally reflected image of a rectangular aperture is optically made to fall on a splitfield photosensor. A difference in focus between the optometer and the subject's eye results in a lateral displacement of the 
rectangle on the photosensor from which an error signal is developed. This error signal drives a high-speed servo on the optometer to a new position that nulls the error signal, and, thus, the difference in focus results. The second piece of equipment, the focus stimulator, is a variation of the basic Badal optometer (see Ogle, 1961, pp. 234). The focus stimulator keeps all targets at the same brightness and size, so these cues cannot be used by the subjects to judge apparent distance. The device is described in detail elsewhere (Crane \& Cornsweet, 1970).

Stimulus. The subjects were presented a black " $X$ " target subtending a constant visual angle of $2.9 \mathrm{deg}$, with target illumination held constant at about $140 \mathrm{~cd} / \mathrm{m}^{2}$, well above the luminance level required for accommodation. The target focus was presented in a sinusoidal alternation from $.0 \mathrm{D}$ to $4.0 \mathrm{D}$ at a frequency of $.4 \mathrm{~Hz}$, exactly the same frequency as in Experiment 1 .

Instructions and Procedure. Each subject was informed that this was an experiment designed to measure his ability to maintain focus on a target that was constantly changing focus for $6.5 \mathrm{~min}$. There were no instructions other than that he should attempt to hold the target in focus as well as possible.

\section{Results and Discussion}

Figure 2 indicates the mean accommodative (full) amplitude over 13 consecutive 30 -sec time blocks. Thus, each subject's data point consists of 12 averaged peakto-peak amplitude values. The results indicate that, over the 6.5-min period, the subjects' range of accommodation tended to go from an initial $2.76 \mathrm{D}$ to $1.98 \mathrm{D}$. This is an average decrease of about $28 \%$. The average (midpoint) of the responses was observed, by inspection, to be overwhelmingly toward the visual far point, in excess of $95 \%$ of the trials. Or, in other words, the accommodative response in the near direction was clipped.

A simple analysis of variance for the task effects over the 13 time blocks indicated a significant effect $[F(12,60)=6.924, p<.001]$. Analysis of variance tests for linear and curvilinear regression (Hays, 1973, pp. 685) indicated an overwhelmingly linear trend $[F(1,60)=$ $34.660, \mathrm{p}<.001$ ]. A best-fit linear least squares line

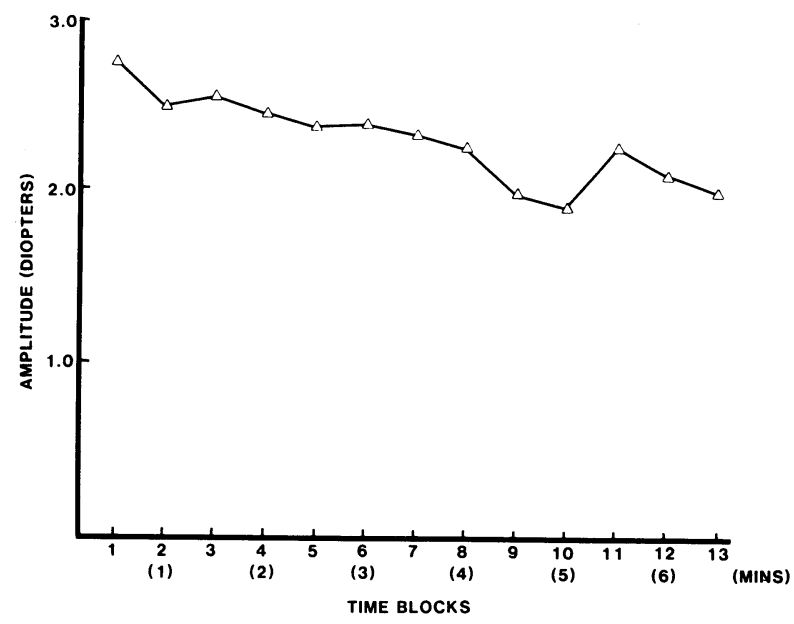

Figure 2. Mean accommodative response amplitude over $6.5 \mathrm{~min}$ of tracking a 0 - to 4-D sinusoidally moving target, in diopters. $(\mathbf{N}=6$. $)$ through the data indicated a slope of $-.057 \mathrm{D}$ per time period, or an effective shortening of the accommodative range by $.114 \mathrm{D} / \mathrm{min}$.

As in Experiment 1, analysis of variance for phase lag failed to indicate any significant differences between time blocks $(p>.05)$. Hence, it would appear that the subject did not have any difficulty keeping pace with the target. Considering that in most kinds of muscular fatigue, both the range and the reaction time of responses are together degraded, this would be a most unusual fatigue effect (see Gartner \& Murphy, Note 2). Contrary to the predictions of Stronghold (Note 3 ), only the accommodative range, not the time to accommodate, is affected by this prolonged task.

\section{GENERAL DISCUSSION}

Comparisons of Experiments 1 and 2 indicate there are significant losses of $1.7 \mathrm{deg}$ of visual angle over a range of $15.4 \mathrm{deg}$ of visual angle while tracking a $.4-\mathrm{Hz}$ target for $6.5 \mathrm{~min}$; for accommodation, there is a short-term reduction of $.75 \mathrm{D}$ over a range of $2.76 \mathrm{D}$ of accommodative tracking. However, it is also worth noting that neither experiment showed any tendency toward increasing or decreasing phase lag. This lag would be expected with both muscular fatigue and boredom/ inattention (Singleton, Fox, \& Whitfield, 1971).

There is an anomaly in the types of responses observed in both this paper and the observations of Geacintov and Peavler (1974) and Saito and Tanaka (in press) that will require further study. The phenomenon of pupillary dilation and accommodation pushing toward the visual far point has been proposed by Malmstrom et al. (1980) and Malmstrom et al. (Note 1) as indicative of a general sympathetic arousal mechanism. Therefore, if Experiments 1 and 2 had been observed to effect a linear increase in the amplitude of pursuit eye movements and a shift of the accommodation response from the far to the near point, we would have been prepared to implicate a parasympathetic (or a sympathetic inhibition) arousal model of visual fatigue. However, this is clearly not the case, as pupillary constriction and an accommodative far shift are incompatible responses under any autonomic response model. Therefore, we are led to consider the possibility of several alternatives.

First, it could be that the pupillary constriction is a primary visual fatigue effect, and the loss of near accommodation is merely because the narrower pupil does not require as great a range of accommodation as a wider pupil (see Hennessy, Iida, Shiina, \& Leibowitz, 1976). An alternative to this proposal is that the accommodative far shift is the primary visual fatigue effect, and the pupil must close to compensate for the loss of near visual accommodative range. The question of whether the pupillary constriction is driving the restricted accommodative response or vice versa is deserving of further study. There also arises the possibility that pupillary constriction by itself (as suggested by Geacintov \& Peavler, 1974) is an imperfect indicator of visual fatigue, and perhaps the combination of pupillary constriction, an accommodative far shift, and a constriction of pursuit eye movements might be a more valid indicator of visual fatigue.

A final alternative is that visual fatigue could be explained by an opponent-process model. Because pupillary constriction and an accommodative far shift are incompatible autonomic responses, their joint action would, in itself, constitute a fatiguing process; the pupillary constriction might, for instance, be constantly attempting to overcome an accommodative far shift.

The search for a model may, indeed, be further complicated by the addition of other response variables, such as vergence. Smith (1979) has reviewed the possible implications of vergence, 
accommodation, pupil size, and eye movements, but, to the best of our knowledge, there has been no attempt to integrate these responses into a single construct to describe visual fatigue. In any case, the present results show clear performance decrements over time for both pursuit eye movement and dynamic accommodation. These are results that any theory of visual fatigue will have to explain.

\section{REFERENCE NOTES}

1. Malmstrom, F. V., Reed, L. E., \& Randle, R. J. Dynamic eye movements during a secondary task: An objective measure of visual narrowing? Manuscript submitted for publication, University of Southern California, 1981.

2. Gartner, W. B., \& MUrphy, M. R. Pilot workload and fatigue: $A$ critical survey of concepts and assessment techniques (Technical Note D-8365). Washington, D.C: National Aeronautics and Space Administration, November 1976.

3. Stronghold, H. The human time factor in flight. Handbook of human engineering data (2nd ed.). Washington, D.C: U.S. Naval Research Laboratory, 1951.

\section{REFERENCES}

Carmichael, L., \& Dearborn, W. F. Reading and visual fatigue. Boston: Houghton Mifflin, 1951.

Cornsweet, T. N., \& Crane, H. D. Servo-controlled infrared optometer. Journal of the Optical Society of America, 1970, 60, 548-554.

Crane, H. D., \& Cornsweet, T. N. Ocular-focus stimulator. Journal of the Optical Society of America, 1970, 60, 557. Dainoff, M. J., HAPP, A., \& Crane, P. Visual fatigue in VDT operators. Proceedings of the Human Factors Society, 1980, 24, 392-394.

Davson, H. Physiology of the eye (3rd ed.). New York: Academic Press, 1976.

Ferguson, D. A., Major, G., \& Keldoulis, T. Vision at work: Visual defect and the visual demands of tasks. Applied Ergonomics, 1974, 5, 84-93.

Geacintov, T., \& Peavler, W. S. Pupillography in industrial fatigue assessment. Journal of Applied Psychology, 1974, 59, 213-216.

Hays, W. L. Statistics for the social sciences (2nd ed.). New York: Holt, Rinehart, \& Winston, 1973.

Hennessy, R. T., Iida, T., Shina, K., \& Leibowitz, H. W. The effect of pupil size on accommodation. Vision Research, 1976, 16, 587-589.

Kahneman, D., Peavler, W. S., \& Onuska, L. Effects of verbalization and incentive on the pupil response to mental activity. Canadian Journal of Psychology, 1968, 22, 186-196.

Malmstrom, F. V., Randle, R. J., Bendix, J. S., \& Weber, R. J. The visual accommodation response during concurrent mental activity. Perception \& Psychophysics, 1980, 28, 440-448.

Ogle, K. N. Optics. Springfield, Ill: Thomas, 1961.

SaIto, M., \& TANaKa, T. Eyestrain in highly paced inspection work. Ergonomics, in press.

Singleton, W. T., Fox, J. G., \& Whitfield, D. (Eds.). Measurement of man at work. London: Taylor \& Francis, 1971.

Sмiтh, W. A. A review of literature relating to visual fatigue. Proceedings of the Human Factors Society, 1979, 23, 362-366.

Tinker, M. B. Recent studies of eye movements in reading. Psychological Bulletin, 1958, 55, 215-231.

Weber, R. J. Ocular fatigue. Archives of Ophthalmology, 1950, 43, 257-264.

(Received for publication April 2, 1981.) 